
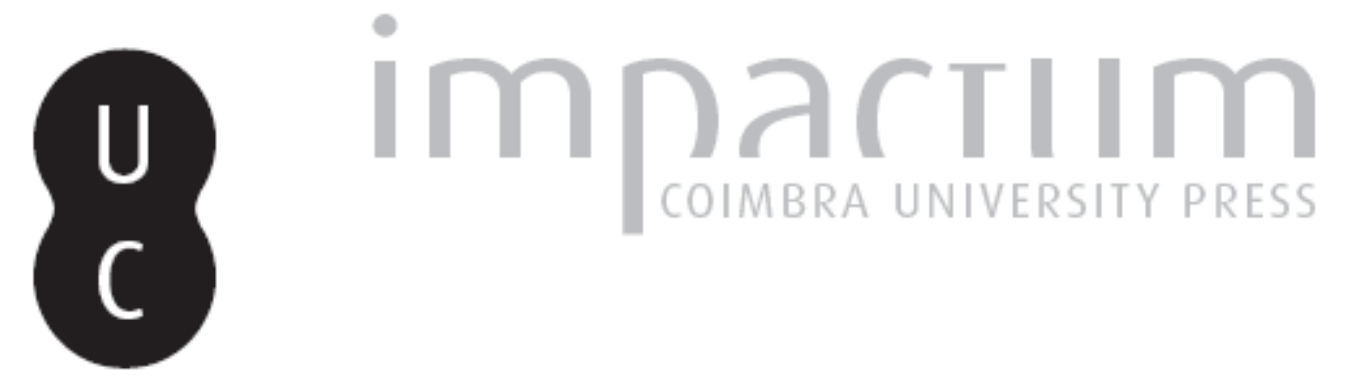

\title{
O problema do livre arbítrio e da intervenção divina na instrução de Ptah-Hotep
}

\author{
Autor(es): $\quad$ Silva, André de Campos
}

Publicado por: Centro de História da Universidade de Lisboa

URL persistente:

URI:http://hdl.handle.net/10316.2/23771

DOI:

DOI:http://dx.doi.org/10.14195/0871-9527_19_1

Accessed : $\quad$ 26-Apr-2023 12:47:57

A navegação consulta e descarregamento dos títulos inseridos nas Bibliotecas Digitais UC Digitalis, UC Pombalina e UC Impactum, pressupõem a aceitação plena e sem reservas dos Termos e Condições de Uso destas Bibliotecas Digitais, disponíveis em https://digitalis.uc.pt/pt-pt/termos.

Conforme exposto nos referidos Termos e Condições de Uso, o descarregamento de títulos de acesso restrito requer uma licença válida de autorização devendo o utilizador aceder ao(s) documento(s) a partir de um endereço de IP da instituição detentora da supramencionada licença.

Ao utilizador é apenas permitido o descarregamento para uso pessoal, pelo que o emprego do(s) título(s) descarregado(s) para outro fim, designadamente comercial, carece de autorização do respetivo autor ou editor da obra.

Na medida em que todas as obras da UC Digitalis se encontram protegidas pelo Código do Direito de Autor e Direitos Conexos e demais legislação aplicável, toda a cópia, parcial ou total, deste documento, nos casos em que é legalmente admitida, deverá conter ou fazer-se acompanhar por este aviso.

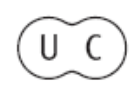



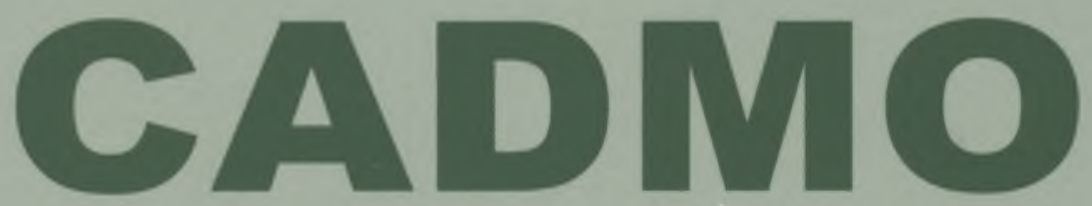

Revista de História Antiga

\author{
Centro de História \\ da Universidade de Lisboa
}

19

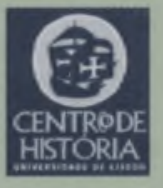

430 =

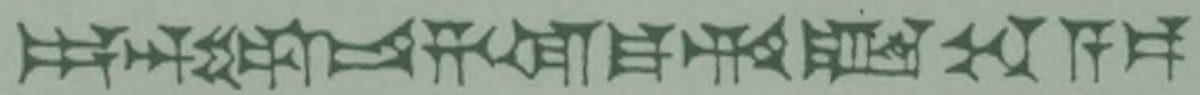

MHNIN AEI $\Delta$ E $\Theta E A ~ \Pi H \Lambda H I A \triangle E \Omega$ 


\title{
O PROBLEMA DO LIVRE ARBÍTRIO E DA INTERVENÇÃO DIVINA NA INSTRUÇÃO DE PTAH-HOTEP
}

\author{
ANDRÉ DE CAMPOS SILVA \\ Universidade de Lisboa \\ andre.silva.tvd@gmail.com
}

\section{Resumo}

$\mathrm{Na}$ Instrução de Ptah-hotep, liberdade humana e intervenção divina convivem lado a lado. Para perceber em que medida os Egípcios se consideravam livres nas suas escolhas e que características pode assumir a intervenção de deus nos assuntos humanos, importa definir a concepção humana e a concepção divina segundo Ptah-hotep. Com este estudo pretende-se sobretudo colocar perguntas e suscitar problemáticas sobre esta aporia intemporal.

Palavras-chave: Ka; coração; autocontrolo; destino; determinação divina; dádiva de deus; Maet; responsabilidade moral.

\section{Abstract}

In the Instruction of Ptah-hotep human freedom and divine intervention live side by side. In order to understand how the Egyptians did considered themselves free in their choices and what characteristics did god's intervention in human affairs assume, it matters to define human conception and divine conception according to Ptah-hotep. With this study one mainly intends to raise queries and problematics regarding this timeless aporia.

Key words: Ka; heart; self-possession; fate; divine determination; god's gift; Maet; moral responsibility. 
O problema do livre arbítrio está sem dúvida presente em todas as religiões. Faz igualmente parte da especulação filosófica, sendo ainda hoje um tema debatido quer na esfera académica quer na religiosa. Aqui proponho-me estudar, do ponto de vista histórico, e utilizando a conhecida Instrução de Ptah-hotep, a forma como os antigos Egípcios entendiam o livre arbítrio humano e as modalidades da intervenção divina.

O tema do problema do livre arbítrio e da intervenção divina em Ptah-hotep foi-me sugerido ao estudar esse texto sapiencial do Império Antigo, pela justaposição de exortações do professor $(s b 3)$ ao aluno (sb3ty) e, por vezes na mesma máxima, de certas declarações de influenciação do comportamento de um indivíduo por parte de deus $(n t \underline{r})$. Vejamos o seguinte exemplo:

Se escutaste o que eu te disse,

Todos os teus planos irão para a frente, (507-8)

$[\ldots]$

Aquele que deus ama é aquele que ouve;

Aquele que deus odeia não ouve.

É o coração que faz do seu proprietário

Alguém que ouve ou alguém que não ouve. $(545-51)^{(1)}$

No início do epílogo, o autor da instrução sugere ao discípulo que escolha seguir os seus ensinamentos. Porém, umas linhas mais à frente, afirma que só aquele que deus ama ouve. Interessa-me, por conseguinte, estudar a intensidade com que se afirma o livre arbítrio humano, por um lado, e a intervenção divina, por outro.

Apesar de outros documentos, como A Aventura de Sinuhe, incluírem referências pertinentes à dialéctica entre liberdade humana e intervenção divina, decido tomar como centro nuclear deste estudo a Instrução de Ptah-hotep por se tratar de um texto de carácter aforístico e exortativo em que a intervenção divina tem um papel relevante. Esta opção conduz-nos a outra problemática, a do contexto histórico abrangido. Segundo o prólogo da instrução, esta foi redigida pelo vizir Ptah-hotep, no reinado de Djedkaré Isesi, da V dinastia. Esta datação limitaria o contexto da obra até fins do Império Antigo (c. 2660-2180 a. C.(2)). O manuscrito mais antigo de que dispomos, o Papiro Prisse, data, no entanto, da XII dinastia. Como o comprova o processo editorial da instrução ao longo da história egípcia ${ }^{(3)}$, é possível que este manuscrito, redigido em egípcio clássico, seja uma actualização de um original em egípcio antigo. Não obstante existir apenas 
este manuscrito como referência, os especialistas ${ }^{(4)}$ dividem-se entre colocar a data de redacção desde finais do Império Antigo até ao Império Médio (c. 2040-1780 a. C.), passando é claro pelo Primeiro Período Intermediário (c. 2180-2040 a. C.). Naturalmente que uma contextualização abrangente é necessária para estudar este tópico na cultura egípcia. Porém, limito-me aqui a explorar o tema na Instrução de Ptah-hotep.

Neste trabalho proponho-me tratar o problema do livre arbítrio e da intervenção divina na Instrução de Ptah-hotep em duas instâncias: em primeiro lugar, parece-me importante traçar um perfil da antropologia do homem egípcio em Ptah-hotep, e, em segundo lugar, procurarei definir a concepção do deus interventor na história humana.

Note-se ainda algumas limitações que se impõem neste estudo. Além de os antigos Egípcios nunca terem feito um tratado sobre o livre arbítrio, as fontes contextuais são sobretudo do domínio funerário, à excepção de textos literários. Sendo documentos que circulavam entre e para a elite, é possível que o controlo do decoro (decorum) ${ }^{(5)}$ se fizesse sentir nas referências à intervenção divina. Um estudo sobre o livre arbítrio não pode perder de vista o seu contexto, e as possibilidades interpretativas que ele nos permite; caso contrário, arriscamo-nos a uma análise demasiado especulativa. Não podemos, por conseguinte, explicar tudo nem para todas as dimensões da sociedade. Não é possível alargar este estudo a toda a sociedade egípcia porque as fontes disponíveis foram produzidas, como disse, pela elite. Podemos, porém, procurar reconstituir o que os pensadores da elite egípcia consideravam sobre o livre arbítrio e a intervenção divina.

\section{Definição de livre arbítrio}

Gostaria de começar por esclarecer o que se entende neste trabalho por livre arbítrio. Em sentido lato, livre arbítrio é a capacidade que um indivíduo tem de escolher de entre múltiplas (ou pelo menos duas) alternativas. Porém, é preciso esclarecer quais as premissas de que se parte. Podemos considerar duas principais correntes filosófico-religiosas sobre as quais ainda hoje continuam acesos debates: a corrente determinista, que afirma que o universo é determinista, e a liberalista, que defende a possibilidade de liberdade humana. Entre as duas doutrinas existe ainda a corrente compatibilista que afirma que o livre arbítrio é compatível com o determinismo. 
Num universo determinista, a partir de determinadas características iniciais, tudo acontece como estipulado de início, não havendo por conseguinte espaço para o livre arbítrio humano. Se o homem é determinado pela divindade, por exemplo, coloca-se a problemática de a quem atribuir a responsabilidade, sobretudo se o homem cometer transgressões éticas por influência divina. ${ }^{(6)}$

A doutrina que defende a possibilidade de escolha humana afirma que o homem é livre de fazer as suas escolhas, pelo menos no plano moral. Para que tal seja possível é necessário que não haja condicionantes (como a intervenção divina) à liberdade humana e é necessário existir a possibilidade de múltiplas alternativas ${ }^{(7)}$.

Para melhor esclarecer as condições necessárias à possibilidade de livre arbítrio cito Linda Zagzebski: «lf the world is causally determined, my act does not really originate in me. For my act really to be my own, it must have a certain kind of independence of any conditions which make it the case that I cannot do otherwise. My act must be unaffected by the presence or absence of these conditions $[\ldots]^{\left({ }^{(8)}\right.}$.

A temática do livre arbítrio pode ser discutida nos vários assuntos humanos, mas dado que a Instrução de Ptah-hotep foca sobretudo os domínios moral e religioso, é a possibilidade de liberdade humana e intervenção divina no domínio da ética que será aqui considerada. Note-se ainda que em egípcio nunca houve um termo quer para liberdade, quer para livre arbítrio, o que torna o seu estudo simultaneamente mais aliciante e mais difícil.

\section{Concepção antropológica em Ptah-hotep}

Ao lermos a Instrução de Ptah-hotep verificamos claramente que o autor estabelece uma diferenciação entre o indivíduo que possui autocontrolo e o indivíduo que se deixa dominar pelas emoções. Existem ainda três elementos constituintes da antropologia egípcia, o ka $(k 3)$, o ba (b3), e o coração (ib), que desempenham um papel importante nas escolhas e acções do indivíduo.

\section{Dialéctica entre autocontrolo e irreflexão}

Em toda a literatura sapiencial egípcia o sábio é o modelo a seguir, enquanto o ignorante é naturalmente o exemplo a evitar. Uma das principais características do sábio é o autocontrolo. Embora a ex- 
pressão para designar o sábio seja rekh ikhet ( $r h$ iht), literalmente "alguém que sabe alguma coisa»(9), o termo, igualmente aplicado ao sábio, guer (grw), "silencioso», do verbo guer (gr), "ser silencioso", "ser sossegado", ser "calmo»(10), expressa bem a característica desejável de autodomínio. No pólo oposto encontra-se o ignorante, cuja descrição de Ptah-hotep se segue:

Quanto ao ignorante que não ouve,

Nenhuma coisa será feita para ele.

Ele vê o conhecimento na ignorância,

$\mathrm{O}$ que é útil no que é pernicioso

Ele faz tudo o que é detestável,

Pelo que se tem razão para se estar irritado com ele diariamente.

Ele vive do que se morre,

Um discurso distorcido é o seu alimento.

É essa a característica que os funcionários reconheceram

Que é: um morto vivo todos os dias.

As pessoas manterão a distância das suas acções nefastas

Por causa dos muitos azares que se abateram sobre ele todos os dias. $(575-87)^{(11)}$.

Porém, a figura do ignorante não é necessariamente negativa, como se pode verificar na seguinte declaração: "Não tornes o teu coração vaidoso devido ao teu conhecimento, / consulta o ignorante e o sábio" $(52-4)^{(12)}$.

Ptah-hotep não fala apenas do sábio e do ignorante, mas também do que segue o coração, o chemés-ib (šms-ib) ${ }^{(13)}$ e do que obedece ao ventre. De facto, a meu ver existe uma identificação entre o primeiro e o sábio, e entre o segundo e o ignorante, o que será corroborado pela máxima 14 :

Aquele que alcança o coração (i.e., que é de confiança)

É aquele que não se inclina ${ }^{(14)}$ para o discurso do seu ventre. (234-5). [...]

O coração daquele que ouve o seu ventre comete erros;

Ele suscitará desdém em vez de amor. (243-4).

[...]

Aquele que ouve o seu ventre pertence ao inimigo. (248)..(15)

No entanto, tanto o ventre como o coração podem desencadear acções irreflectidas:

Não repitas uma calúnia,

Não a ouvirás. 
É aquele que tem o ventre em fogo que se expressa dessa maneira. $(350-2) \cdot{ }^{(16)}$

Não respondas a uma palavra (agressiva) com emoção (nsr).

Olha para o outro lado, controla-te.

A chama do que tem o coração em fogo espalha-se depressa. (376-8).(17)

Inversamente, o ventre pode-se encontrar calmo:

Um pouco daquilo que se cobiça

Gera a querela naquele que tem o ventre fresco. $(322-3)^{(18)}$

Ambos os elementos constituintes do ser humano podem originar emoções negativas e positivas. Sobretudo, entre o ventre em fogo e o coração em fogo dificilmente haverá distinção de significância. Contudo, embora o coração possa originar acções descontroladas Ptah-hotep exorta o seu leitor a segui-lo(19), enquanto o ventre é associado a um instinto emocional não domesticado pela ética.

As linhas 376-788 indicam livre arbítrio em relação ao que segue o coração. Relativamente ao que age em conformidade com o ventre Ptah-hotep nem sempre the parece atribuir capacidade de escolha:

É o pão que se destina à distribuição que se anseia.

O que tem o ventre vazio é o que se agita,

$\mathrm{E}$ o que sente que é mantido num estado de privação torna-se um agressor. (483-5).

Estando a acção com origem no ventre fora do controlo do agente, poderá deus influenciar as motivações irracionais que o levam a agir? Voltaremos a esta questão mais à frente.

\section{O ka, o ba, e o coração}

O conceito de $k a(k 3)$ é de difícil interpretação e tradução ${ }^{(20)}$. Por uma questão de clarificação epistemológica, podemos dividir o ka em ka interno e externo ${ }^{(21)}$. O ka externo é o habitualmente traduzido por "duplo", e que era alvo do culto funerário, das oferendas do rei (htp-di-nsw $n$ k3 $n N N^{(22)}$ ), e que se pode ver nas representações do deus Khnum, na sua função de criador, a ser criado ao mesmo tempo que o indivíduo. Há ainda o ka de cada indivíduo comum, e o ka do rei ${ }^{(23)}$. 
O ka que nos interessa aqui é o ka do indivíduo comum, ligado às actividades mentais, o $k a$ interno. Andrey Bolshakov afirma que "The mind was usually related to the ba [...], but the word hmt ("think" or "to act as three together") leads one to suppose that there was also an idea of thinking as a trilateral process, with the ka playing an obscure role, along with the ba.»(24)

É esta participação do ka no pensamento e na possibilidade de escolha do indivíduo que nos interessa aqui.

Quer o ka quer o ba, mais conhecidos pelos seus atributos post mortem, estão, segundo alguns textos, activos e presentes enquanto o indivíduo está vivo. Como nota James P. Allen ${ }^{(25)}$ acerca do ba, tal é notório no célebre Diálogo de Um Homem com o Seu Ba, conhecido texto do Império Médio. Na Instrução de Ptah-hotep uma passagem no epílogo sugere-nos igualmente a actividade do ba antes da morte:

O sábio alimenta o seu ba com o que é duradouro,

Para que (o seu ba) esteja contente com ele sobre a terra. $(524-5)^{(26)}$

De facto, também aqui se parece considerar algum tipo de influência por parte do ba sobre o indivíduo, já que este deve procurar a sua aprovação. Dado que Ptah-hotep apenas faz referência ao ba na passagem acima citada, não darei mais seguimento aqui ao possível papel desempenhado pelo ba no livre arbítrio.

Vejamos por agora as instâncias em que o ka intervém nos assuntos humanos em Ptah-hotep:

Se estás entre convidados

À mesa de um superior, (119-20)

$[\ldots]$

Importuná-lo é a abominação do ka. (125)

$[\ldots]$

Quanto ao superior, quando está perante a refeição,

A sua conduta está(27) de acordo com a ordem do seu ka. (135-6)

[...]

É o ka que estende os seus braços:

O superior dará àquele que atingiu a condição de homem (de qualidade). $(139-40)^{(28)}$

Não difames ninguém,

Grande ou pequeno, é a abominação do ka. $(159-60)^{(29)}$

Não reduzas o tempo de "segue-o-coração",

Desperdiçar o seu momento $(3 t)^{(30)}$ é a abominação do ka. $(188-9)^{(31)}$ 
Se ele for recto, se seguir os teus passos,

Tomar bem conta dos teus bens,

[...]

Ele é teu filho, teu ka o gerou. $(199-202,204)^{(32)}$

Daquele que falha em sustentar os amigos

Diz-se: «tem um ka egoísta». (341-2).

[...]

O (bom) ka é o ka pelo qual alguém é mantido. (344) $)^{(33)}$

Se ele se zangar com quem o frustra,

O ka (do mestre) separar-se-á de quem o ama. [...]

No entanto ele providencia juntamente com o deus,

O que ele deseja deverá ser feito para ele.

Quando ele voltar o seu rosto para ti depois de se ter enraivecido,

Haverá paz do seu ka. $(391-7)^{(34)}$

Se deixares o seu conhecimento impressionar o seu senhor (do povo), O teu sustento virá do seu $k a$.

Assim como o ventre do favorito é alimentado,

Também as tuas costas serão vestidas por ele $(k a) .(401-7)^{(35)}$

[...]

Vê, é o ka que ama ouvir. (414) (36)

Como podemos constatar, se o ka não determina o comportamento do indivíduo, pelo menos influencia-o. As passagens "a sua conduta está de acordo com a ordem do seu ka", "é o ka que estende os seus braços", "tem um ka egoísta", "o ka separar-se-á de quem o ama", "haverá paz do seu ka", indicam, pelo menos à superfície, que o ka tem um certo grau de autonomia. Podemos ver o ka como um alter-ego, havendo uma dialéctica entre o eu e o ka. Embora por vezes o eu possa despeitar o ka (como na linha 160), creio que a relação entre o indivíduo e o ka é sobretudo uma relação de cumplicidade, como é expresso, por exemplo, na linha 344.

No papel desempenhado no pensamento pelo $k a$, este pode ser traduzido, segundo Andrey Bolshakov, por "carácter", "natureza", "temperamento", ou "disposição" ${ }^{(37)}$. Enquanto carácter, o ka, que nasce juntamente com o indivíduo a que pertence, poderá ser ainda traduzido, segundo o mesmo autor, por "destino" ou "providência»(38). Hans Goedicke ${ }^{(39)}$ sugere ainda, na sua interpretação das linhas 135-136, que o ka, ao ser a referência de comportamento do indivíduo, seria deste modo "the man's better self, a kind of conscience shaping 
the mundane experience». Saliente-se ainda que o ka "era transmitido pelo criador ao mundo, pelo rei ao povo, e pelos pais aos seus fiIhos" ${ }^{(40)}$. Esta transmissão do ka pelo deus criador $^{(41)}$ sugere algum tipo de intervenção de deus junto do $k a$, o que nos leva às questões: terá o ka autonomia na influência do comportamento humano, ou será, pelo contrário, o próprio ka por sua vez influenciado por deus?

Do ka passemos agora ao coração $(i b)^{(42)}$. O coração é um dos elementos fundamentais da concepção egípcia de indivíduo. O coração era para os antigos Egípcios a sede do pensamento, do conhecimento, da intuição, mas também, como acima vimos, da emoção.

Vejamos de seguida as passagens referentes ao coração que me parecem mais pertinentes para o tema:

Segue o coração (šms-ib) enquanto viveres,

Não cometas excessos em relação ao que foi dito,

Não reduzas o tempo (tr) de "segue-o-coração",

Desperdiçar o seu momento de acção (3t.f) ofende o ka.

Não desperdices tempo em cuidados do dia-a-dia

Para além do necessário para a tua casa;

Acontecem as coisas, segue o coração. $(186-192)^{(43)}$

O coração daquele que ouve o seu ventre comete erros;

Ele suscitará desdém em vez de amor. (243-4)

Segundo David Lorton, a tradução da expressão šms-ib depende do contexto. De acordo com o mesmo autor, ib pode ser traduzido como "consciência", "vontade», ou "desejo", e šms como "seguir», "servir", ou ainda "fazer uso de". O referido autor opta por traduzir esta passagem de Ptah-hotep por "segue a tua consciência". ${ }^{(45)}$ A exortação seguinte, "não cometas excessos em relação ao que foi dito", pode ser relacionada com as linhas 151, "segura-te a maet, não te afastes dela", e 312, "um homem vive uma longa vida quando aplica correctamente a maets ${ }^{(46)}$. As linhas seguintes podem ser interpretadas como um aforismo contra a procrastinação na atenção a ter com o coração. Neste sentido proponho a tradução complementar de "serve o teu coração", no intento do desenvolvimento pessoal.

$\mathrm{Na}$ relação entre o indivíduo e o seu coração, o segundo não é sempre passivo. Na linha 378 ("a chama do que tem o coração em fogo espalha-se depressa"), o descontrolo emocional manifesta-se sob o coração em chamas, e na linha 243 é igualmente o coração que ouve o ventre e leva o indivíduo a cometer erros. Torna-se portanto, 
aparentemente, um paradoxo seguir o coração quando este pode ter comportamentos menos desejáveis. Todavia, as linhas $635-636$ indicam que quando indivíduo e coração sintonizam, o primeiro encontra-se no caminho aconselhado por Ptah-hotep: «ele fará maet, / quando o seu coração tiver agido de acordo com as suas acções.»(47)

Enquanto referência comportamental, saliente sobretudo na já abordada linha 186, o coração parece portar uma consciência ética que o transcende. Como nota Siegfried Morenz ${ }^{(48)}$, em períodos posteriores a inspiração divina ao coração, quer para actos construtivos quer para actos destrutivos, está bem documentada. Poderá o coração em Ptah-hotep estar igualmente acessível à inspiração divina? Voltaremos a esta questão no capítulo seguinte.

\section{Concepção de deus em Ptah-hotep}

A segunda etapa do nosso trabalho é definir a concepção de deus segundo a Instrução de Ptah-hotep enquanto interventor nos assuntos humanos.

Um dos problemas levantados pelo chamado "deus das instruções" - e de outras fontes, tais como nomes próprios ${ }^{(49)}$ e as biografias de privados - é o anonimato de deus. As únicas divindades nomeadas na Instrução de Ptah-hotep são Osíris e Hórus.

As duas principais correntes interpretativas do significado do deus não nomeado são a que defende que esta divindade se trata de um Deus monoteísta e transcendente, e a que argumenta que não se especifica qual o deus a que se refere para não promover partidarismos e para que um deus em particular (Ré, Ptah, Tot, etc.) que seja necessário em determinada situação ou local possa estar implícito no termo genérico.

Da primeira corrente interpretativa faz parte Joseph Vergote ${ }^{(50)}$ cujo trabalho continua a ser um ponto de referência no estudo da "noção de deus" nas instruções egípcias. Vergote defende que o deus anónimo das instruções revela um monoteísmo dos sábios. Esta interpretação é hoje considerada inapropriada para o pensamento egípcio pela maior parte dos egiptólogos.

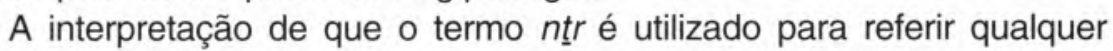
divindade do panteão egípcio consoante os locais e as circunstâncias em que o leitor se encontra é actualmente considerada a mais plausível e é defendida, entre outros autores, por Erik Hornung ${ }^{(51)}$. Segundo 
este autor, o uso do vocábulo $n t \underline{r}$ nas instruções tem de ser analisado à luz do seu contexto. As instruções destinavam-se aos futuros funcionários, que, na sua actividade profissional, se poderiam encontrar em diversas localidades, cada uma com o seu deus. Por conseguinte, o termo indefinido $n t \underline{r}$ aplica-se a qualquer deus sob cuja influência o funcionário se possa encontrar ${ }^{(52)}$. A hipótese de um monoteísmo está, por conseguinte, para estes autores, excluída. Mesmo quanto à hipótese de um henoteísmo, tal parece ser improvável, como afirma Michael Fox ${ }^{(53)}$, uma vez que o henoteísmo implica a exclusão de outros deuses o que não parece ser o caso nas instruções.

Para o estudo de deus em Ptah-hotep podemos utilizar algumas das categorias propostas por Joseph Vergote ${ }^{(54)}$, nomeadamente as categorias de "senhor dos acontecimentos", "providência dos homens», «juiz e retribuidor das boas e más acções». Cito aqui as passagens da instrução que se enquadram nas categorias de Vergote relevantes para esta discussão:

Enquanto «senhor dos acontecimentos»:

Nunca o terror ( $h r$ ) das pessoas foi bem sucedido,

$\mathrm{O}$ que deus ordena é que é o que se torna bem sucedido.

Pensa em viver em ${ }^{(55)}$ paz

$\mathrm{O}$ que eles (deuses) ${ }^{(56)}$ dão vem por si mesmo. $(115-8)^{(57)}$

Aquele que deus ama é aquele que ouve;

Aquele que deus odeia não ouve.

É o coração que faz do seu proprietário

Alguém que ouve ou alguém que não ouve. $(545-51)^{(58)}$

Como "providência dos homens":

Comer está sob o conselho de deus. (142) $)^{(59)}$

Se lavrares e houver prosperidade no campo,

E se deus o deixar prosperar na tua mão (161-2).

[...]

É o que está só que deus acolhe. (173)(60)

As coisas (bens materiais) não vêm por si.

É a sua lei para aqueles que eles (deuses) amam, (181-2)

[...]

É o deus que o faz notável,

(E) que o protege (mesmo enquanto) dorme. (184-5) (61)

Pessoas com um grande (wr) coração são um dom de deus. $(247)^{(62)}$ 
Sustenta os teus amigos com o que tiveres,

Tem-no pela graça de deus. $(339-40)^{(63)}$

Não ponhas a confiança do teu coração na acumulação dos teus bens materiais,

$\mathrm{O}$ que te chegou foi dado por deus. (máxima 30)(64)

Vê, um bom filho é uma dádiva de deus. $(152)^{(65)}$

"Juiz e retribuidor das boas e más acções":

Não exercerás terror entre as pessoas,

Deus castigará do mesmo modo. $(99-100)^{(66)}$

Aquele que se mostrou hostil contra ti incorrerá no desfavor deles (dos deuses),

(Pois) um obstáculo foi infligido no ventre.

Aquele que eles guiam não comete erros;

Aquele que eles privam de barco não atravessa. $(216-9)^{(67)}$

Sendo deus o "senhor dos acontecimentos" e "providência dos homens", pode o livre arbítrio humano coexistir com a intervenção divina? Relativamente ao "senhor dos acontecimentos" consideremos agora as linhas 545-551.

As duas primeiras linhas apresentam um problema gramatical. Dependendo da forma verbal que considerarmos ser a intencionada pelo autor, o sujeito ou é o homem ou é deus. Na tradução que apresento aqui, interpretei os verbos mrrw («amar») e msddw ("odiar») como sendo formas relativas imperfectivas. Uma alternativa com um significado semelhante é o particípio imperfectivo passivo: "o amado de deus é aquele que ouve; o odiado de deus não ouve». A primeira frase, com a mesma forma verbal, pode ainda ser traduzida como "aquele que ouve é amado de deus", colocando a ênfase na acção humana. A meu ver há pelo menos mais uma forma verbal que se pode adequar a este contexto. Embora morfologicamente não seja de se esperar encontrar a terminação em $w$ é possível que ambos os verbos sejam particípios imperfectivos activos, o que altera completamente o sentido do texto: "aquele que ama deus é aquele que ouve; aquele que odeia deus não ouve". Como nota Zbiněk Žába, que no entanto optou pela mesma tradução que aqui proponho, esta interpretação estaria em conformidade com as duas frases que se seguem ${ }^{(68)}$. Será este um indicador de que tal interpretação é a mais correcta? 
$\mathrm{Na}$ minha opinião não necessariamente, uma vez que se conjugarmos estas passagens com as linhas 116 ("o que deus ordena é que é o que se torna bem sucedido"), e 216-217 ("aquele que se mostrou hostil contra ti incorrerá no desfavor deles, / (pois) um obstáculo foi infligido no ventre"), verificamos que para Ptah-hotep deus intervém nos assuntos humanos e até no próprio indivíduo. Tratar-se-ão as linhas 545-551 de um paradoxo? Ou será que Ptah-hotep pretendeu dividir a responsabilidade entre homem e deus? Coloco esta questão por algo de semelhante ocorrer no célebre texto sobre A Aventura de Sinuhe. Quando explica ao rei Senuseret I as razões que o levaram a exilar-se na Ásia Sinuhe acusa, por um lado, os seus medos e emoções que o dominaram por completo e, por outro, o deus que determinou (SA, B229-30) a sua fuga. Note-se que o termo utilizado por Sinuhe é o termo usualmente traduzido por "destino". Tanto quanto me é possível saber, em nenhum texto do Império Antigo e do Império Médio o destino surge como uma entidade autónoma como virá a acontecer no Império $\mathrm{Novo}^{(69)}$; o destino é sempre manipulado geralmente por um deus e, em algumas fórmulas dos "Textos das Pirâmides", pelo rei. Voltaremos à questão do destino mais à frente.

As linhas 550-1, "é o coração que faz do seu proprietário / alguém que ouve ou alguém que não ouve», conduzem-nos à interrogação feita no capítulo precedente: poderá o coração na Instrução de Ptah-hotep estar acessível à inspiração divina? As frases acabadas de citar colocam a capacidade de livre arbítrio à responsabilidade do coração, pelo que em Ptah-hotep a influência de deus não parece efectuar-se no coração. A intervenção divina no indivíduo ao nível físico aparenta, no entanto, estar presente nas linhas 216-217, "aquele que se mostrou hostil contra ti incorrerá no desfavor deles (dos deuses), / (pois) um obstáculo foi infligido no ventre." Nesta instância é provável que o pronome sufixo plural .sn se reporte aos deuses, uma vez que na reinterpretação do manuscrito L2 da XVIII dinastia (Império Novo, c. 1560-1070 a. C.) "eles" é substituído por "deus». A palavra traduzida por "obstáculo», sdb, pode ter ainda os significados de «impedimento» e de «mal». Deus pode portanto, ainda que em reacção retributiva, controlar o indivíduo através do seu ventre.

Enquanto na passagem antecedente a intervenção divina pode ser interpretada como tendo sido provocada pela rebeldia do filho que desobedece ao discípulo de Ptah-hotep, as duas linhas que se seguem parecem comportar um carácter universalista: "aquele que eles guiam não comete erros $(\mathrm{nnm})$; / aquele que eles privam de barco 
não atravessa". Se relacionarmos a primeira frase com "o erro $(n n m)$ entra naquele que não ouve" $(572)^{(70)}$, voltamos à problemática das linhas 545-546; se na primeira frase é deus que mantém o indivíduo no bom caminho, na linha 572 este é responsabilizado por não ouvir. A responsabilidade parece ser abordada na frase "aquele que eles privam de barco não atravessa». O verbo $d 3 i$, "atravessar", é aqui utilizado como metáfora para alcançar a vida desejada no Além. Se o indivíduo que é guiado pelos deuses não erra, podemos concluir que o indivíduo que não o é erra. Aparentemente o indivíduo é colocado na dependência de deus para ser bem sucedido no julgamento após a morte. Neste caso podemos estar perante uma predestinação ${ }^{(71)}$ divina do futuro do indivíduo depois da morte. A noção de que deus determina aspectos da vida do indivíduo parece conviver com a liberdade de escolha deste. Em que extensão se afirma a determinação do primeiro e a liberdade do segundo no contexto geral do Império Antigo e do Império Médio é uma interrogação a que não darei seguimento aqui.

Enquanto a determinação divina da máxima 12 nos pode parecer negativa, há outra dimensão na relação entre homem e deus que se nos afigura benquista. Esta dimensão é o que podemos classificar, por uma questão de conveniência, de providencialista. Um exemplo são as linhas 161-162: "se lavrares e houver prosperidade no campo, e se deus o deixar prosperar na tua mão". Aqui lavrar o campo tem um significado bifronte. Por um lado tem um sentido de abundância em riqueza, mas por outro é uma metáfora da reprodução humana ${ }^{(72)}$. O homem está dependente de deus quer para produzir riqueza quer para procriar.

$\mathrm{Na}$ nossa mundividência actual, em que se valoriza o esforço individual e a independência, a dependência de deus pode-nos parecer uma restrição à iniciativa humana. No entanto, para os antigos Egípcios esta dependência não tinha de ser humilhante. Pelo contrário, é possível que este género de intervenção divina fosse desejado e considerado benfazejo. De facto, é o próprio autor da instrução que o sugere: "pensa em viver em paz, / o que eles dão vem por si mesmo." (115-8). Ao viver de acordo com os preceitos de Ptah-hotep o discípulo torna-se apto a receber as dádivas dos deuses.

Podemos por conseguinte falar de uma relação de parceria e de cumplicidade na relação entre homem e deus enquadrada na dimensão providencialista do segundo, e daí que possamos estabelecer duas atitudes fundamentais de deus para com a humanidade: a determinação e a dádiva. A primeira tem componentes negativas, enquanto a segunda é estimada. 
A hostilidade de deuses para com a humanidade não era estranha ao pensamento egípcio, como bem nota Siegfried Morenz ${ }^{(73)}$. A ideia de que um deus pode contribuir para uma condenação a priori do homem estaria assim em conformidade com uma certa hostilidade divina ${ }^{(74)}$. Esta característica da intervenção divina na Instrução de Ptah-hotep leva-nos à seguinte interrogação: serão os deuses egípcios bons? Ou serão ambivalentes?

Continuando a definição da concepção de deus em Ptah-hotep, chegamos agora à relação entre deus e o destino (̌̌s). Como acima ficou dito, até ao Império Novo o destino será sempre uma entidade passiva geralmente controlada por deus. Ora, como afirma Siegfried Morenz, neste âmbito deus intervém na história na qualidade de "senhor do destino" ${ }^{(75)}$. Na Instrução de Ptah-hotep existe apenas uma referência a šs:

Se estás a tentar conhecer a verdadeira natureza de um amigo, (463) [...]

(e se) ele concretizar um acto que te irrite, (472)

[...]

Não the respondas com um acto de hostilidade, (476)

[...]

Nunca o seu momento $(s p)$ falhou em vir;

Não se pode escapar daquele que o determinou ( $\left.\check{s}^{\prime} s w\right)$. (479-80). ${ }^{(76)}$

Dado o teor da máxima 33 as duas últimas frases provavelmente referem-se à morte do desviante por retribuição divina. Com efeito, na ausência de um antecedente para o particípio perfectivo activo, deus é o sujeito mais plausível(77). Resta saber que tipo de acção está subentendida a $\breve{3}$ e qual o grau de imputabilidade do sujeito passivo. Se o pronome dependente $s w$ referir $s p$ é a morte do indivíduo que é determinada, inserindo-se no paradigma da acção-retribuição. Se pelo contrário sw designar o indivíduo, é o seu comportamento que é predestinado, culminando num castigo desde logo anunciado.

Contudo, ao invés do que é documentado sobretudo em fontes do Império Novo e períodos posteriores ${ }^{(78)}$, a extensão do tempo de vida parece estar dependente do indivíduo e não da graça de deus: "um homem vive uma longa vida quando aplica correctamente a maet».

Coloco agora uma última questão sobre deus à qual não responderei aqui. Será a intervenção divina controlada pela divindade? $\mathrm{Na}$ criação egípcia, o potencial vivificante, o espaço aquoso primordial do Nun, precede todos os deuses, com a possível excepção do deus criador ${ }^{(79)}$. Tendo os deuses origem no Nun poderá este controlá-los? 


\section{A noção de maet como reguladora do livre arbítrio humano e da intervenção divina}

O conceito de maet é fundamental em todos os aspectos da civilização egípcia. Num estudo como este, que conjuga ética e religião, a maet tem um papel decisivo na compreensão do fenómeno em estudo.

Posto isto, vejamos agora a quinta máxima da Instrução de Ptah-hotep:

Se és um líder,

Responsável por orientar um grande número (de pessoas),

Procura toda a ocasião para seres eficiente,

De modo a que o teu comportamento seja irrepreensível.

Grande é a maet, duradoura a sua eficácia.

Não foi perturbada desde o tempo de Osíris.

$\mathrm{O}$ que transgride as leis ( $h p w)$ é punido,

Isto escapa à visão do homem ganancioso.

A iniquidade vai-se apoderar da quantidade,

Mas o mal nunca sucederá em trazer o seu momento de acção, em segurança, ao porto.

Ele (o que pratica as más acções) diz: «Adquiri para o benefício da minha função".

Chega o fim, a maet permanece.

O homem (justo) diz: "esta é a terra de meu pai» (84-98). ${ }^{\left({ }^{(80)}\right.}$

Nesta máxima afirma-se a possibilidade de livre arbítrio humano: "procura toda a ocasião para seres eficiente". A frase «isto escapa à visão do homem ganancioso" relembra-nos o indivíduo que se deixa dominar pelo ventre. Outra declaração imputa autonomia ao homem: "segura-te a maet, não te afastes dela" (151). A locução "o que transgride as leis $(h p w)$ é punido" é reveladora. As acções humanas são avaliadas com maet e as leis como referência. Ao ser imputável e passível de responsabilização moral, o homem sai com o livre arbítrio reforçado. A avaliação ética alcança a sua maior expressão no julgamento dos mortos, que, segundo alguns autores, terá até tido origem ainda no Império Antigo ${ }^{(81)}$. Este julgamento é justamente uma das principais limitações da divindade. Como bem refere J. Sainte Fare Garnot $^{(82)}$, o julgamento dos mortos encoraja a liberdade humana. Não obstante a sua responsabilidade depender da sua liberdade de escoIha, o homem é confrontado com a maet e não com os deuses. Os 
deuses devem, por conseguinte, sujeitar-se à ordem cósmica. A responsabilidade do homem constitui assim o espaço reservado à autonomia humana. Todavia se, como acima se conjecturou, deus pode efectivamente determinar as acções do homem para o mal, o julgamento post mortem torna-se naturalmente redundante, levando a que haja uma excepção na mediação da relação entre deus e homem, bem como uma justaposição de conceitos.

\section{Conclusão}

Como pudemos constatar, o problema do livre arbítrio e da predestinação divina em Ptah-hotep é um tema complexo e que aqui só pôde ser tratado resumidamente. Do percurso que fizemos podemos salientar a complexidade do processo de pensamento na antropologia egípcia, que se dá com a conjugação dos elementos antropológicos ka, ba e coração. Cada um destes, independentemente e em conjunto, condiciona o indivíduo na sua possibilidade de escolha. Por isto não quero dizer que impossibilita $o$ indivíduo de escolher livremente, mas que influencia a sua escolha. Vimos igualmente que sem a direcção do coração o ventre pode controlar as acções do indivíduo.

Relativamente à noção de deus verificámos que a divindade em Ptah-hotep, além de influenciar as acções do indivíduo, também é benquista. Estas duas dimensões podem ser, no entanto, divergentes: enquanto a providência é positiva a intervenção no indivíduo por vezes é negativa. Convivem assim, na Instrução de Ptah-hotep, discursos opostos que ora apontam para a liberdade humana ora para uma certa determinação divina. Tal justaposição de ideias é só por si relevante; se o autor da instrução as registou é porque ambas as concepções coexistiam e eram consideradas válidas.

Dada a popularidade da instrução, o conteúdo da mesma estaria certamente em conformidade com o que o decoro - cujo condicionamento é constantemente relembrado por John Baines - permitia aos membros da elite escreverem e, por consequência, poderá ser considerada como representante do pensamento intelectual do Império Antigo e do Império Médio. Seja como for, há que ter em consideração que a relação deus-homem é mediada pela maet. E é contra o pano de fundo deste conceito ético que as acções humanas são avaliadas e a responsabilidade imputada. 


\section{Notas}

(1) Tadução própria.

(2) Em todas as referências sigo a cronologia disponível em Luís Manuel de ARAÚJO (dir.), Dicionário do Antigo Egipto, Lisboa: Editorial Caminho, 2001, 15.

(3) Transcrição dos originais em hierático, tradução, e comentário do Papiro Prisse e cópias posteriores em Zbyněk ŽÁBA, Les Maximes de Ptaḥhotep, Praga: Nakladatelvstí Československé Akademie Věd, 1956.

(4) R. J. WILLIAMS, "The Sages of Ancient Egypt in the Light of Recent Scholarship", Journal of the American Oriental Society 101.1 (1981), 9, referencia alguns destes autores.

(5) John BAINES, "Society, Morality, and Religious Practice", in Byron E. Shafer (ed.), Religion in Ancient Egypt: Gods, Myths and Personal Practice, Ithaca: Cornell University Press, 1991, 138.

(6) Veja-se lleana MARCOULESCO, "Free Will and Determinism" (1987), in Lindsay Jones (ed.), The Encyclopedia of Religion, $2 .^{\text {a }}$ ed., vol. 5, Nova lorque, 2005, 3199-3200 col. dir.

(7) Acerca da necessidade de alternativas possíveis como condição essencial no livre arbítrio veja-se Robert KANE, "Responsability", excerto republicado em John Martin Fischer (ed.), Free Will, Critical Concepts in Philosophy, vol. II: Free Will: Determinism, Nova lorque: Routledge, 147-148.

(8) Linda ZAGZEBSKI, «Foreknowledge and human freedom», em Philip L. Quinn, Charles Taliaferro, A Companion to Philosophy of Religion, Blackwell Companions to Philosophy, Oxford: Blackwell Publishers, 1997, 295.

(9) Michael V. FOX, "Two Decades of Research in Egyptian Wisdom Literature", ZÄS 107 (1980), 127.

(10) Cf. Raymond O. FAULKNER, A Concise Dictionary of Middle Egyptian, Oxford: Griffith Institute, 1991, 290.

(11) Apresento esta tradução com base nos textos de Miriam LICHTHEIM, Ancient Egyptian Literature (AEL): A Book of Readings, vol. I: The Old and Middle Kingdoms, Berkeley, Los Angeles, Londres: University of California Press, 1973, 74-75, e de Christian JACQ, The Wisdom of Ptah-hotep: Spiritual Treasures from the Age of the Pyramids, Londres: Constable, 2004 (tradução do original francês de 2006), 141-142. Algumas palavras foram-me elucidadas pelo texto hieroglífico disponivel na versão de Jacq. Indico a numeração das linhas no texto principal.

(12) Miriam LICHTHEIM, AEL I, 63.

(13) Ver citação da máxima 11 na p. 9.

(14) No manuscrito L2 iwty phr.f dd $m$ ht.f é reinterpretado como iwty sdm.f $n$ dd ht.f (cf. Zbyněk ŽÁBA, Les Maximes de Ptaḥhotep, 34). Dada a antítese desta declaração na linha 243 e o uso do verbo sdm, "ouvir", opto por traduzir phr por «inclinar". Duas interpretações diferentes são as de Vincent TOBIN, "One who is trustworthy / is one who will not spread talk around the community" ("The Maxims of Ptahhotep", em William Kelly Simpson (ed.), The Literature of Ancient Egypt: An Anthology of Stories, Instructions, Stelae, Autobiographies, and Poetry, New Haven e Londres: Yale University Press, 2003, 136), e de Raymond O. FAULKNER, "A trustworthy man is one who does not distort speech in his mind" ("The Maxims of Ptahhotpe", em William Kelly Simpson (ed.), The Literature of Ancient Egypt: An Anthology of Stories, Instructions and Poetry, New Haven e Londres: Yale University Press, 1973, 165). 
(15) Christian JACQ, The Wisdom of Ptah-hotep: Spiritual Treasures from the Age of the Pyramids, 87-89.

(16) Idem, ibidem, 107.

(17) Traduzido a partir de idem, Ibidem, 111-2, e Vincent A. TOBIN, "The Maxims of Ptahhotep", em William Kelly Simpson (ed.), The Literature of Ancient Egypt: An Anthology of Stories, Instructions, Stelae, Autobiographies, and Poetry (2003), 129-48.

(18) Traduzido a partir de Christian JACQ, The Wisdom of Ptah-hotep: Spiritual Treasures from the Age of the Pyramids, 101-2, e Zbynék ŽÁBA, Les Maximes de Ptaḥhotep, 87.

(19) Cf. máxima 11.

(20) Para uma introdução a este complexo conceito veja-se Luís Manuel de ARAÚJO, "Ka», em Dicionário do Antigo Egipto, 469-470.

(21) A sugestão desta distinção é de Andrey O. BOLSHAKOV, "Ka", in Donald B. Redford (ed.), The Oxford Essential Guide to Egyptian Mythology, Nova Iorque: Berkleey Books, 2002, 179 col. esq.

(22) "Oferenda que faz o rei ao ka de NN".

(23) Esta distinção é feita por o ka do rei se transferir de um monarca para outro, mantendo assim a legitimidade do novo governante e a sua componente divina (cf. Andrew A. GORDON, "The K3 as an Animating Force", JARCE 33 (1996), 33 col. dir., e Andrey O. BOLSHAKOV, "Ka", in Donald B. Redford (ed.), The Oxford Essential Guide to Egyptian Mythology, $180 \mathrm{col}$. dir.).

(24) Andrey O. BOLSHAKOV, "Ka", in Donald B. Redford (ed.), The Oxford Essential Guide to Egyptian Mythology, $179 \mathrm{col}$. dir.

(25) "Ba», em Donald B. REDFORD (ed.), The Oxford Essential Guide to Egyptian Mythology, 27 (col. dir.)-28 (col. esq.).

(26) Miriam LICHTHEIM, AEL, I, p. 73.

(27) No original egípcio: shr.f hft wd k3.f. Hans Goedicke propõe que se acrescente iri ao começo da frase, por a expressão iri shr estar bem documentada no contexto da emissão de ordens, tirando a ênfase ao "capricho" do ka: "a sua conduta deverá estar de acordo com a ordem do seu ka" (vide Hans GOEDICKE, "Ptahhotep Maxim 7: Only Etiquette?", GM 189 (Göttingen: 2002), 44). Opto por manter a frase como está preservada no Papiro Prisse por o seu sentido estar em conformidade com outras passagens sobre o $\mathrm{ka}$.

(28) Christian JACQ, The Wisdom of Ptah-hotep: Spiritual Treasures from the Age of the Pyramids, 71-73).

(29) Idem, ibidem, 75.

(30) Sobre st («momento") veja-se Siegfried MORENZ, Egyptian Religion, Ithaca e Nova Iorque: Cornell University Press, 1960 (tradução inglesa de 1973 a partir do original alemão por Ann E. Keep), 76-77.

(31) Christian JACQ, The Wisdom of Ptah-hotep: Spiritual Treasures from the Age of the Pyramids, 80.

(32) Miriam LICHTHEIM, AEL I, 66.

(33) Idem, ibidem, 69; Christian JACQ, The Wisdom of Ptah-hotep: Spiritual Treasures from the Age of the Pyramids, 105. 
(34) Miriam LICHTHEIM, ibidem, 70.

(35) Idem, ibidem, 71.

(36) Christian JACQ, The Wisdom of Ptah-hotep: Spiritual Treasures from the Age of the Pyramids, 117.

(37) Andrey O. BOLSHAKOV, "Ka", in Donald B. Redford, The Oxford Essential Guide to Egyptian Mythology, $179 \mathrm{col}$. dir., Raymond O. FAULKNER, em William Kelly Simpson (ed.), The Literature of Ancient Egypt: An Anthology of Stories, Instructions, and Poetry, 169 , traduz o termo ka na sua primeira ocorrência da máxima 27 por "boa vontade", o que aponta igualmente no sentido de o ka ser um elemento constitutivo da personalidade.

(38) Andrey O. BOLSHAKOV, ibidem.

(39) GM 189, 45.

(40) James P. ALLEN, The Ancient Egyptian Pyramid Texts, Writings from the Ancient World, Atlanta: Society of Biblical Literature, 2005, 434.

(41) Veja-se, por exemplo, a fórmula TP 600: "Atum-Khepri! [...] Tu colocaste os teus braços à volta deles (Chu e Tefnut) como braços-ka para que o teu ka pudesse estar neles. Atum, coloca os teus braços à volta de Pepi Neferkaré como braços ka para que - ka de Pepi Neferkaré possa estar nele, firme para o resto da eternidade" (cf. Idem, ibidem, 269).

(42) Dois dos estudos mais exaustivos do coração publicados em Portugal são Rogério Ferreira de SOUSA, O Coração e o Homem no Antigo Egipto: Contributos para a Compreensão de Uma "Psicologia" Antiga, Lisboa, 1998, tese de mestrado em História e Cultura Pré-Clássica apresentada à Faculdade de Letras da Universidade de Lisboa em 1999; Rogério Ferreira de SOUSA, A Simbólica do Coração no Antigo Egipto: estudo de antropologia religiosa sobre a representação da consciência, tese de doutoramento apresentada à Faculdade de Letras da Universidade do Porto em 2007.

(43) Miriam LICHTHEIM, AEL I, 66; Christian JACQ, The Wisdom of Ptah-hotep: Spiritual Treasures from the Age of the Pyramids, 80-81. Esta máxima é também traduzida e comentada em David LORTON, "The Expression Šms-ib", JARCE 7 (1968), 42 col. dir.-43 col. esq.

(44) Christian JACQ, The Wisdom of Ptah-hotep: Spiritual Treasures from the Age of the Pyramids, 89.

(45) David LORTON, "The Expression Šms-ib», 41.

(46) Christian JACQ, The Wisdom of Ptah-hotep: Spiritual Treasures from the Age of the Pyramids, 74, 100. A segunda parecença foi-me sugerida por David LORTON, "The Expression Šms-ib", 42 col. dir.

(47) Interpreto ir.f como um sdm.f prospectivo, e ir.n ib.f como um sdm.n.f circunstancial. Tomei como referência na tradução Vincent A. TOBIN, "The Maxims of Ptahhotep", em William Kelly Simpson (ed.), The Literature of Ancient Egypt: An Anthology of Stories, Instructions, Stelae, Autobiographies, and Poetry (2003), 148; Christian JACQ, Ibidem, 153, e Zbyněk ŽÁBA, Les Maximes de Ptaḥhotep, 171.

(48) Egyptian Religion, 64-6.

(49) Para exemplos de nomes com o vocábulo indefinido de $n t \underline{r}$ veja-se Erik HORNUNG, Conceptions of God in Ancient Egypt: The One and the Many, Ithaca e Nova lorque: Cornell University Press, 1982 (tradução e revisão por John Baines), 45-46. 
(50) Joseph VERGOTE, "La notion de Dieu dans les livres de sagesse égyptiens", em Les Sagesses du Proche Orient Ancien (Bibliothéque des Centres d'Etudes supérieures spécialisés: Travaux du Centre d'Etudes supérieures spécialisé d'Histoire des religions de Strasbourg, Paris, 1963), 159-190. Sobre os autores que defendiam a existência de um monoteísmo na religião egípcia veja-se Erik HORNUNG, Conceptions of God in Ancient Egypt: The One and the Many, 18-30.

(51) Erik HORNUNG, ibidem, 57-9. Esta teoria foi no entanto formulada por Herman KEES, Der Gottërglaube im Alten Ägypten, Berlim: 1977, apud Michael V. FOX, "Two Decades of Research in Egyptian Wisdom Literature", 124.

(52) Veja-se, além de Erik HORNUNG, ibidem, Marie-Ange BONHÊME, "Divinity" (traduzido do francês por Elizabeth Schwaiger), em Donald B. Redford, The Oxford Essential Guide to Egyptian Mythology, 107. Saliente-se ainda que já Batiscombe Gunn havia igualmente proposto esta interpretação (The Instruction of Ptahhotep and the Instruction of Ke'gemni: the Oldest Books in the World, apud Joseph VERGOTE, "La notion de Dieus dans les livres de sagesse égyptiens", 160.

(53) "Two Decades of Research in Egyptian Wisdom Literature", 124-125.

(54) "La Notion de Dieus dans les livres de sagesse égyptiens", 168-170.

(55) Literalmente, «no interior».

(56) Raymond O. FAULKNER, "The Maxims of Ptahhotpe", em William Kelly Simpson (ed.), The Literature of Ancient Egypt: An Anthology of Stories, Instructions, and Poetry (1973), 162, traduz o pronome pessoal sufixo "eles" por "homens". Contudo a maior parte dos autores, incluindo eu próprio, vêem aqui uma referência aos deuses e não aos homens.

(57) Tradução própria.

(58) Tradução própria.

(59) Miriam LICHTHEIM, AEL I, 65.

(60) Idem, ibidem, 66.

(61) Christian JACQ, The Wisdom of Ptah-hotep: Spiritual Treasures from the Age of the Pyramids, 78-79.

(62) Idem, ibidem, 89.

(63) Miriam LICHTHEIM, AEL I, 69.

(64) Traduzido a partir de Christian JACQ, The Wisdom of Ptah-hotep: Spiritual Treasures from the Age of the Pyramids, 121.

(65) R. O. FAULKNER, "The Maxims of Ptahhotpe", em William Kelly Simpson (ed.), The Literature of Ancient Egypt: An Anthology of Stories, Instructions and Poetry (1973), 175.

(66) Tradução própria.

(67) Christian JACQ, The Wisdom of Ptah-hotep: Spiritual Treasures from the Age of the Pyramids, 84. Enquanto Jacq traduz "um obstáculo foi infligido quando estava (ainda) no útero", interpreto h.t não como útero mas como ventre. Sobre este e outros problemas gramaticais levantados nesta passagem veja-se ainda Frank T. MIOSI, "God, Fate and Free Will in Egyptian Wisdom Literature", in Gerald E. Kadish, Geoffrey E. Freeman (eds.), Studies in Philology in Honour of Ronald James Williams, Toronto: SSEA Publications, 1982, 79-80, e Zbyněk ŽÁBA, Les Maximes de Ptahhotep, 131-132. 
(68) Cf. Les Maximes de Ptahhotep, 164.

(69) Neste período o destino passa de conceito abstracto a conceito divinizado na pessoa de Chai. Veja-se José das Candeias SALES, As Divindades Egípcias: Uma Chave Para a Compreensão do Egipto Antigo, Lisboa: Editorial Estampa, 1999, 329-330.

(70) Tradução própria.

(71) Uso aqui o termo "predestinação" apenas no sentido de o futuro ser predeterminado de antemão. É provável que a predestinação no sentido radical não existisse no pensamento egípcio, como afirma John Baines: «In a context such as Egypt it is therefore inappropriate to speak of a rigid "predestination" comparable with that of some forms of Christianity. Notions such as "grace" may circumvent that predestination to some extent; Egyptian conceptions are generally still more flexible." ("Contexts of Fate: Literature and Pratical Religion", em Christopher Eyre, Anthony Leahy e Lisa Montagno Leahy (eds.), The Unbroken Reed, Studies in the Culture and Heritage of Ancient Egypt in Honour of A. F. Shore, Londres: The Egypt Exploration Society, 1994, 36).

(72) Cf. Zbyněk ŽÁBA, Les Maximes de Ptaḥ̣otep, 125.

(73) Siegfried MORENZ, Egyptian Religion, 26-27.

(74) Esta hostilidade é particularmente notória na literatura funerária: "Qualquer deus que erga o seu braço (em oposição) quando a face de Unas está voltada para te venerar e para te chamar sobre o corpo de Unas, deus, e sobre o seu nariz, deus - ele não terá pão, ele não terá obra entre os seus irmãos os deuses; [...] a porta da barca nocturna não será aberta para ele, a porta de barca diurna não será aberta para ele». Citação em James P. ALLEN, The Ancient Egyptian Pyramid Texts, 58 (fórmula 212 de Unas, TP 307 na numeração de Kurt Sethe).

(75) Egyptian Religion, 72-4.

(76) Traduzido a partir de Christian JACQ, The Wisdom of Ptah-hotep: Spiritual Treasures from the Age of the Pyramids, 125-7.

(77) A mesma opinião é expressa em Zbyněk ŽÁBA, Les Maximes de Ptahhotep, 157.

(78) Um exemplo é o hino a Amon de Leiden: "ele aumenta ou reduz o tempo de vida" (cf. Sigfried MORENZ, Egyptian Religion, 71).

(79) Segundo Geraldine Pinch o deus criador já se encontrava no Nun num estado de inércia (cf. Egyptian Mythology: A Guide to the Gods, Goddesses, and Traditions of Ancient Egypt, Nova lorque: Oxford University Press, 2002, 59).

(80) Christian JACQ, The Wisdom of Ptah-hotep: Spiritual Treasures from the Age of the Pyramids, 66-68.

(81) S. G. F. BRANDON, The Judgement of the Dead: An Historical Comparative Study of the Idea of a Post-Mortem Judgement in the Major Religions, Londres: Weidenfield and Nicolson Ltd, 1967, 6-48. O autor dá exemplos para um julgamento no Império Antigo sobretudo dos "Textos das Pirâmides" e das autobiografias; Siegfried MORENZ, Egyptian Religion, 126-30. Na sua argumentação sobre a origem de um julgamento após a morte a partir da $\mathrm{V}$ dinastia, Morenz cita algumas passagens de Ptah-hotep que apontam para um castigo divino (supõe-se que naturalmente após um julgamento) no Além.

(82) «Discussion de La Communication de M. H. Brunner («Der Freie Wille Gottes in der Ägyptischen Weisheit")", em Les Sagesses du Proche Orient Ancien, 118. 


\section{Bibliografia consultada}

Luís Manuel de ARAÚJO (dir.), Dicionário do Antigo Egipto, Lisboa: Editorial Caminho, 2001.

John BAINES, "Society, Morality, and Religious Practice", em Byron E. Shaefer (ed.), Religion in Ancient Egypt: Gods, Myths and Personal Practice, Ithaca e Londres: Cornell University Press, 1991.

Andrey O. BOLSHAKOV, "Ka", in Donald B. Redford (ed.), The Oxford Essential Guide to Egyptian Mythology, Nova lorque: Berkley Books, 2002.

José Nunes CARREIRA, Filosofia Antes dos Gregos, Mira-Sintra, Mem Martins: Publicações Europa-América, 1994.

Raymond O. FAULKNER, "The Maxims of Ptahhotpe", em William Kelly Simpson (ed.), The Literature of Ancient Egypt, New Haven, CT e Londres, Yale University Press, 1973, 159-76.

Michael V. FOX, «Two Decades of Research in Egyptian Wisdom Literature», ZÄS 107 (1980), 120-35.

Hans GOEDICKE, «Ptahhotep Maxim 7: Only Etiquette?», GM 189 (Göttingen: 2002), 41-45.

Christian JACQ, The Wisdom of Ptah-hotep: Spiritual Treasures from the Age of the Pyramids, Londres: Constable, 2004 (tradução do original francês).

Erik HORNUNG, Conceptions of God in Ancient Egypt: The One and the Many, Ithaca e Nova lorque: Cornell University Press, 1982 (tradução e revisão por John Baines).

Miriam LICHTHEIM, Ancient Egyptian Literature: A Book of Readings, vol. I: The Old and Middle Kingdoms, Berkley, Los Angeles, Londres: University of California Press, 1973.

David LORTON, «The Expression šms-ib», JARCE 7 (1968), 41-54.

lleana MARCOULESCO, “Free Will and Determinism» (1987), em Lindsay Jones (ed.), The Encyclopedia of Religion, 2. ${ }^{\text {a }}$ ed., vol. 5, Nova lorque, 2005, 3199-202.

Frank T. MIOSI, «God, Fate and Free Will in Egyptian Wisdom Literature», em Gerald E. Kadish, Geoffrey E. Freeman (eds.), Studies in Philology in Honour of Ronald James Williams, Toronto: SSEA Publications, 1982, 70-111.

Siegfried MORENZ, Egyptian Religion, Ithaca e Nova lorque: Cornell University Press, 1960 (tradução inglesa de 1973 a partir do original alemão por Ann E. Keep).

Rogério Ferreira de SOUSA, O Coração e o Homem no Antigo Egipto: Contributos para a Compreensão de uma "Psicologia" Antiga, Lisboa, 1998, tese de mestrado em História e Cultura Pré-Clássica apresentada à Faculdade de Letras da Universidade de Lisboa em 1999.

Vincent A. TOBIN, "The Maxims of Ptahhotep», em William Kelly Simpson (ed.), The Literature of Ancient Egypt: An Anthology of Stories, Instructions, Stelae, Autobiographies, and Poetry, New Haven e Londres: Yale University Press, 2003, 129-148.

Thomas F. TRACY, “Divine Action», em Philip L. Quinn, Charles Taliaferro, A Companion to Philosophy of Religion, Blackwell Companions to Philosophy, Oxford: Blackwell Publishers, 1997, 299-304.

Joseph VERGOTE, "La notion de Dieu dans les livres de sagesse égyptiens", em Les Sagesses du Proche Orient ancient (Bibliothéque dês Centres d’Etudes supérieures 
spécialisés: Travaux du Centre d'Etudes supérieures spécialisé d'Histoire des religions de Strasbourg, Paris, 1963), 159-190.

Dewey D. WALLACE Jr., "Free Will and Predestination: An Overview» (1987 e 2005), em Lindsay Jones (ed.): The Encyclopedia of Religion, 2. ${ }^{a}$ ed., vol. 5, Nova lorque, 2005, 3202-3206.

R. J. WILLIAMS, "The Sages of Ancient Egypt in the Light of Recent Scholarship". Journal of the American Oriental Society, 92 (Abril-Junho 1972): 214-221.

Zbyněk ŽÁBA, Les Maximes de Ptaḥhotep, Praha: Nakladatelvstí Československé Akademie Vèd, 1956.

Linda ZAGZEBSKI, «Foreknowledge and human freedom», em Philip L. Quinn, Charles Taliaferro, A Companion to Philosophy of Religion, Blackwell Companions to Philosophy, Oxford: Blackwell Publishers, 1997, 291-298. 